\title{
Determining the energy demand towards sustainable machining of AISI 316L stainless steel
}

\author{
Rusdi Nur $^{1,2, *}$, Asmeati Sabir ${ }^{3}$, Muhammad Arsyad Suyuti ${ }^{1}$, and Abdul Salam ${ }^{1}$ \\ ${ }^{1}$ Mechanical Engineering Department, Politeknik Negeri Ujung Pandang, 9024 Makassar South Sulawesi, Indonesia \\ ${ }^{2}$ Centerof Materials and Manufacturing Engineering, Politeknik Negeri Ujung Pandang, 9024 Makassar South Sulawesi, Indonesia \\ ${ }^{3}$ Study Program of Mechanical Engineering, Universitas Fajar, 90231 Makassar South Sulawesi, Indonesia
}

\begin{abstract}
Minimizing the energy demand of machining operations has become mainly in the manufacturing field; encouraged by the significantly increase in the energy cost and the environmental effects due to high levels of energy demand. The energy consumed to cutting operation in turning process was divided into two sections, i.e. the energy used to setup machine and the energy consumed to cutting process. The total energy demand of machining process can be estimated with prediction equations based on material removal rate (MRR) and cutting force. This paper aims to promote an approach to predict and calculated the total energy demand of cutting operation performing the sustainable in turning process. The results presented that the estimated of energy demand values are almost similar to the actual values about 7.3 percent than the actual energy demand.
\end{abstract}

\section{Introduction}

Consumption of natural resources and pollution resulting from the life of technical products has become a global environmental problem and has resulted in increased political pressure and stronger regulation applied to producers and users of those products [1]. The existence of sustainable development activities in production has been adopted in a cost-effective route industry to improve economic, environmental, and social performance.

Sustainable production as a problem solving in dealing issues of higher energy demand and costs, including applicable in the fields of engineering, such as the machining process [2]. In the sustainable production, reduction of energy consumption becomes an important consideration in addressing the issue of energy $[3,4]$.

In production processes, improving sustainability performance and saving money can be performed by minimizing energy demand. The production process highly requires the energy, and production is also integrated with machinery. Thus, the reduction of energy demand to generate parts can be contributed by reducing energy demand in machinery.

A prerequisite in targeting energy reduction in a machining process is the capability to determine the total energy used during machining. This identification of energy usage in a machining process can be done by studying a particular machining process in detail [5]. Previous works on identifying the machining process and deriving the calculation for total energy demand were reported by Rajemi et al. [4] and $\mathrm{He}$ et al. [6], to name some. The first stated that total energy during machining is the sum of the energy consumed by the machine during setup processing, during cutting process, during tool change, and to produce a cutting tool and normalized per cutting edge. The last observed that total energy was from constant energy demand (corresponding to idle condition) and from variable energy consumption (related to cutting power). In this paper, the first approach is used. The machining process studied is turning of hardened steel under dry condition (no cutting fluid). The cutting tool used is carbide insert, which means the machining process is in extreme range of its capability [7]. The energy calculated is total energy consumed in machining the hardened steel starting from the beginning of cutting process (when the tool is still fresh) until the cutting tool reaches its tool life.

In this paper, the energy demand of turning process is investigated by using three methods. The experimental was performed on the turning of AISI 316L austenitic stainless steel.

\section{Determining Energy Demand}

The energy demand in turning process can be obtained using the measuring the power meter includes voltage, current, power and energy demand. Furthermore, the total of energy demand $(E)$ can be formulated using a modified equation [4], as following equation:

$$
E=E_{1}+E_{2}+E_{3}+E_{4}
$$

The energy consumed during the setup processing as $E_{1}$, during the cutting operation as $E_{2}$, for changing a tool as $E_{3}$, and for resulting cutting tools as $E_{4}$. In this paper, the energy used to cutting process for calculation of

\footnotetext{
${ }^{*}$ Corresponding author: rusdinur@poliupg.ac.id
} 
energy consumption, namely $E_{C}$. Thus, equation (1) can be modified as below:

$$
E_{C}=E_{1}+E_{2}
$$

$E_{l}$ is the energy that is used to setup operation and can be formulated from the amount of power demand during timing setup, as shown in the equation:

$$
E_{l}=P_{0} \cdot t_{1}
$$

where $P_{0}$, namely idle power, is the power required for devices to support the machine, such as the computer and fans, motor, coolant pump etc. The power required by a machine tool using a three-phase motor, $P_{o}$, is formulated as follow [8]:

$$
P_{0}=V \cdot I \cdot \sqrt{3} \cdot \operatorname{Cos} \phi
$$

where $V$, is the voltage, $I$ is the current [A], and $\operatorname{Cos} \phi$ is the power factor $(0.8-1.0)$. The value of $V$ and $I$ can be obtained from the machining data that shown in the control panel of CNC lathe machine, $t_{l}$ is the time needed to setup the machine $[\mathrm{s}]$.

$E_{2}$ is the energy demand during cutting process and can be formulated by the power engine module for removing material, as developed by [9] in equation below.

$$
E_{2}=\left(P_{0}+k \cdot \dot{v}\right) t_{2}
$$

where $\left(P_{0}+k \cdot \dot{v}\right)$ can defined as the electrical power required $(P)$ for machining [9] with following equation below:

$$
P=P_{0}+k \cdot \dot{v}
$$

where, $P$ is the power [W] consumed by machining process, $P_{0}$ is the power [W] consumed by all machine modules for a machine operating without loading, $k$ is the specific energy requirement $\left[\mathrm{Ws} / \mathrm{mm}^{3}\right]$ in cutting operations (Table 1 ), and $\dot{v}$ is the material removal rate (MRR), in $\left[\mathrm{mm}^{3} / \mathrm{s}\right]$ which can be calculated as follows:

$$
\dot{v}=V_{C} \cdot f \cdot a_{p}
$$

where $f$ is the rate of feeds $(\mathrm{mm} / \mathrm{rev})$ and $V_{c}$ is the cutting speed $(\mathrm{m} / \mathrm{min})$, and $a_{p}$ isthe depth of cut $(\mathrm{mm})$.

Table 1. Energy specific for Cutting (k).

\begin{tabular}{|l|c|}
\hline \multicolumn{1}{|c|}{ Material } & $\boldsymbol{k}$ value $\left[\mathbf{W s} / \mathbf{m m}^{\mathbf{3}}\right]$ \\
\hline Aluminum alloy & $0.4-1.0$ \\
\hline Cast iron & $1.1-5.4$ \\
\hline Copper iron & $1.4-3.2$ \\
\hline High-temperature alloy & $3.2-8.0$ \\
\hline Magnesium alloy & $0.3-0.6$ \\
\hline Nickel alloy & $4.8-6.7$ \\
\hline Refractory alloy & $3-9$ \\
\hline Stainless steel & $2-5$ \\
\hline Steels & $2-9$ \\
\hline Titanium alloy & $2-5$ \\
\hline
\end{tabular}

Value of $(k \cdot \dot{v})$ can be summarized as the cutting power. Thus, the above equation for the total power consumption in cutting process $\left(P_{t}\right)$ was assumed as follow:

$$
P=P_{0}+P_{C}
$$

where $P_{c}$ is the cutting power which is the product of cutting force and cutting speed $[10,11]$ :

$$
P_{C}=F_{C} \cdot V_{C}
$$

where $V_{c}$ was cutting speed $(\mathrm{m} / \mathrm{min})$, and $F_{c}$ was cutting force that supplies the energy needed for the cutting operation. Thus, the cutting process have an equation as follow:

$$
P=P_{0}+\left(F_{C} \cdot V_{C}\right)
$$

As described in equation 1, the energy requirement for the machining process can be summarized based on the cutting force and the cutting power (measured by using power meter) with following equation:

$$
\begin{aligned}
& E_{2}=\left(P_{0}+F_{C} \cdot V_{C}\right) t_{2} \\
& E_{2}=\left(P_{0}+P_{C}\right) t_{2}
\end{aligned}
$$

Based on theequation 2, theenergy consumed for cutting process can be calculated by equation below:

$$
\begin{aligned}
& E_{C}=P_{0} t_{1}+\left(P_{0}+P_{c}\right) t_{2} \\
& E_{C}=P_{0} t_{1}+\left(P_{0}+k \cdot \dot{v}\right) t_{2} \\
& E_{C}=P_{0} t_{1}+\left(P_{0}+F_{c} \cdot V_{c}\right) t_{2}
\end{aligned}
$$

\section{Experimental Setup}

In this paper, the turning process was performed using the ALPHA 1350S 2-axis CNC lathe machine (100 - 6000 rpm of spindle speed ranges and $8.3 \mathrm{~kW}$ of horse power and) under without cooling conditions using uncoated carbide tool (Mitsubishi's UTi20T) with featured $0.8 \mathrm{~mm}$ nose radius and designated as TCLNR 2020K12. The cutting parameters were selected after the recommendations given by the tool's manufacturer. The criteria of tool life were adjusting at $0.2 \mathrm{~mm}$ of maximum flank wear width or until the tool was severely damage.

The workpiece material used in the turning process was AISI 316L austenitic stainless steel, with a diameter of $150 \mathrm{~mm}$ and length of $300 \mathrm{~mm}$. The composition of AISI 316L was detailed in Tables 2.

Table 2. Composition of AISI 316L.

\begin{tabular}{|c|c|r|}
\hline Composition & Min & Max \\
\hline $\mathrm{C}$ & - & 0.03 \\
\hline $\mathrm{Mn}$ & - & 2.00 \\
\hline $\mathrm{Si}$ & - & 0.75 \\
\hline $\mathrm{P}$ & - & 0.05 \\
\hline $\mathrm{S}$ & - & 0.03 \\
\hline $\mathrm{Cr}$ & 16 & 18.00 \\
\hline $\mathrm{Mo}$ & 2 & 3.00 \\
\hline $\mathrm{Ni}$ & 10 & 14.00 \\
\hline $\mathrm{N}$ & - & 0.10 \\
\hline
\end{tabular}

The experimental setup was developed using nine experiments as shown in Table 3 . It was conducted to repetition for each parameter. 
Table 3. Cutting parameters.

\begin{tabular}{|l|c|c|c|}
\hline \multicolumn{1}{|c|}{ Levels } & Low & Centre & High \\
\hline Cutting speed $(\mathrm{m} / \mathrm{min})$ & 90 & 150 & 210 \\
\hline Feed $(\mathrm{mm} / \mathrm{rev})$ & 0.10 & 0.16 & 0.22 \\
\hline Depth of cut $(\mathrm{mm})$ & \multicolumn{3}{|c|}{0.4} \\
\hline Coolant & \multicolumn{3}{|c|}{ No Fluid } \\
\hline
\end{tabular}

\section{Results and discussion}

The energy demand was calculated by using Equation 13 to 15 . The calculation results for energy demand based on experimental, cutting force and material removal rate (MRR) are shown in Figures 1, 2 and 3 for feeds of 0.10, 0.16 and $0.22 \mathrm{~mm} / \mathrm{rev}$ respectively.

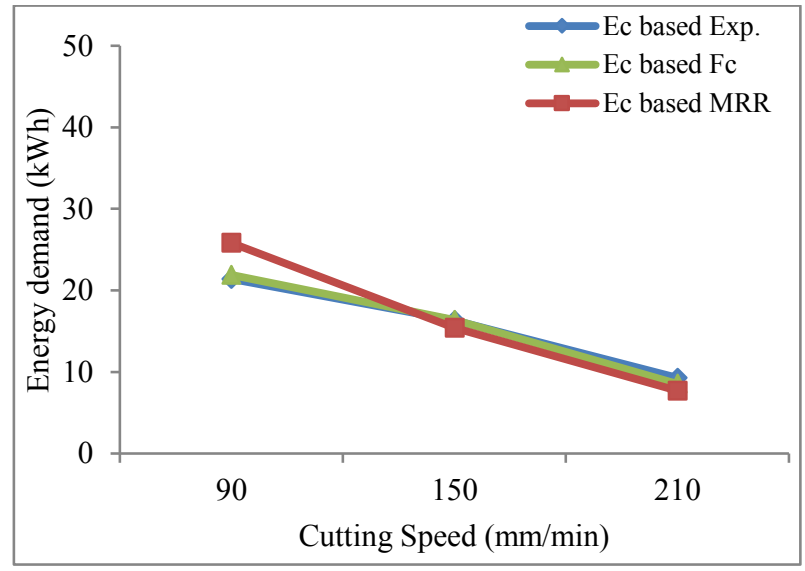

Fig. 1.Plotting energy demand for $0.10 \mathrm{~mm} / \mathrm{rev}$ of feed in different of cutting speeds.

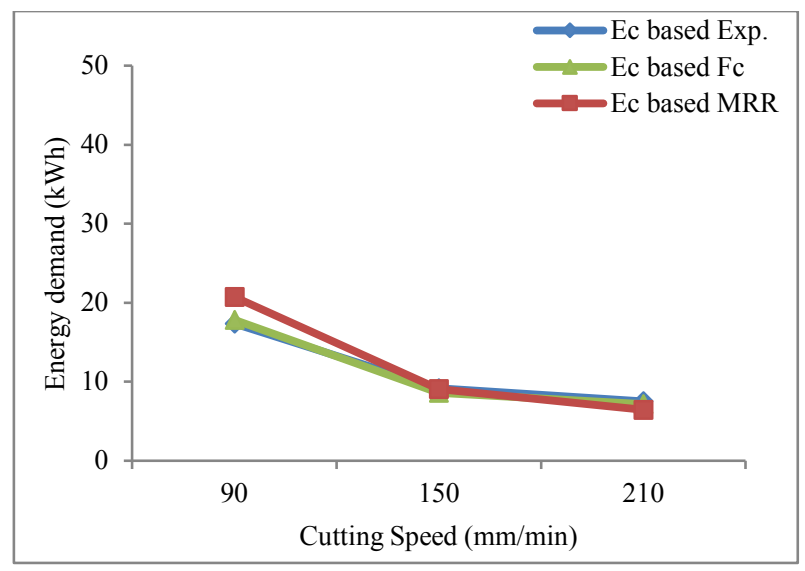

Fig. 2.Plotting energy demand for $0.16 \mathrm{~mm} / \mathrm{rev}$ of feed in different of cutting speeds

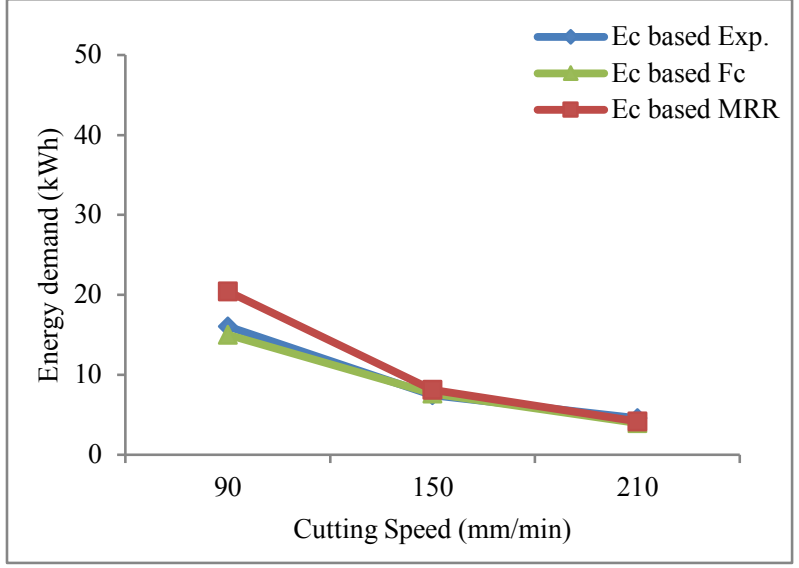

Fig. 1.Plotting energy demand for $0.22 \mathrm{~mm} / \mathrm{rev}$ of feed in different of cutting speeds

Figures 1, 2 and 3 illustrate further comparison between the actual based on experiments and the estimated energy demand based on cutting force and material removal rate. All estimated energy demand values of the cutting operations are almost similar to the actual values, and the estimated value of the total energy demand is average difference of 7.3 percent than the actual one. In machining processes especially $\mathrm{CNC}$ machining, the energy demand that required was dominantly influenced by cutting parameters i.e. speed of cutting, feed rate and depth of cut. The cutting speed was more significant for the energy demand than feed rate. It found that the increasing cutting speed will be increase the energy demand.

These results were confirmed by Velchev et al [12], their study presented that the increasing cutting speed decreases the energy demand when turning of steel 17G2SAF using insert grade GC4235. Nur et al. [13,14] also investigate the turning of AISI 316L stainless steel using coated carbide, they concluded that the equations prediction developed for machining output can be useful in determining the optimum cutting parameters. Another study was conducted by Nur et al. for turning of aluminum alloys [15-17] and carbon steel [18-19]. The research result stated that the energy demand was influenced by cutting speed. Increasing the cutting speed will decrease energy demand, because the cutting process was faster.

\section{Conclusions}

In this paper, the turning of AISI 316L stainless steel using an uncoated cemented carbide was studied and concluded as following results:

- The energy demand was significantly affected by the cutting speed as compared with feeds.

- Increasing the cutting speed can be decrease the energy demand for particular machining, it is due to shorter the cutting time during the machining process.

- Determining the energy demand in the machining process can be performed with the three approaches, namely: direct measurement in the experiments, calculations using data cutting force and MRR. 
We would like to acknowledge to Politeknik Negeri Ujung Pandang for the registration and we are also thankful to Center of Materials and Manufacturing of PoliteknikNegeri Ujung Pandang for supporting the research.

\section{References}

1. Jegatheesan, V., J.L. Liow, L. Shu, S.H. Kim, and C. Visvanathan. J. of Cleaner Prod. 17(7): 637-643. (2009)

2. Hanafi, I., A. Khamlichi, F.M. Cabrera, E. Almansa, and A. Jabbouri. J. of Cleaner Prod.33: 1-9.(2012)

3. Park, C.-W., K.-S. Kwon, W.-B. Kim, B.-K. Min, S.J. Park, I.-H. Sung, Y. Yoon, K.-S. Lee, J.-H. Lee, and J. Seok. Inter. J. of Prec. Eng. and Manuf. 10(5): 151-173.(2009)

4. Rajemi, M.F., P.T. Mativenga, and A. Aramcharoen. J. of Cleaner Prod. 18(10-11): 1059-1065.(2010)

5. Chapman, P.F. Energy Policy. 2(2): 91-103.(1974)

6. He, Y., B. Liu, X. Zhang, H. Gao, and X. Liu., J. of Cleaner Prod.23(1): pp. 167-174.(2012)

7. Noordin, M.Y., D. Kurniawan, Y.C. Tang, and K. Muniswaran. Inter. J. of Adv. Manuf. Tech.60(9-12): 853-863.(2012)

8. John, P. $1^{\text {st }}$ ed. New York: McGraw-Hill Co. Inc.(2000)

9. Gutowski, T., J. Dahmus, and A. Thiriez. 13th CIRP Inter. Conf. on Life Cycle Eng. (2006)

10. Kalpakjian, S. and S. Schmid. $4^{\text {th }}$ ed. London: Prentice-Hall Inter. (UK) Ltd. (2001)

11. Astakhov, V.P. and X. Xiao. Mach. Sci. and Tech. 12(3): 325-347. (2008)

12. Velchev, S., I. Kolev, K. Ivanov, and S. Gechevski, J. of Cleaner Prod. 80: pp. 139-149. (2014)

13. Nur, R., M. Noordin, S. Izman, and D. Kurniawan. Procee. of the Inst. of Mech. Eng., Part E: J. of Pro. Mech. Eng.. 231 (4) : 676-683. (2017)

14. Nur, Rusdi. J.Eng. App. Sci. ARPN 12 (6): 18851889. (2017)

15. Nur, Rusdi, D. Kurniawan, M. Y. Noordin, and S. Izman. Proc. Manuf. 2: 558-562. (2015)

16. Nur, Rusdi, M. Y. Noordin, S. Izman, and Denni Kurniawan. Adv. Mater. R., 845:799-802. (2014)

17. Nur, Rusdi, Muhammad Arsyad Suyuti, and Tri Agus Susanto. AIP Conf. Proc.1855: 020002. (2017)

18. Susanto, Tri Agus, and Rusdi Nur. IOP Conf. Series: Mater. Sci. \& Eng.191 (1): 012028. (2017)

19. Nur, Rusdi, Muhammad Arsyad Suyuti, and Tri Agus Susanto. AIP Conf. Proc.1855 (1): 020002. (2017) 